\title{
Compression Hosiery and foam Sclerotherapy
}

\section{As Meias de Compressão Elástica e a Escleroterapia}

\author{
Zarca C. ${ }^{1}$ \\ ${ }^{1}$ França. \\ E-mail: charcraz74@gmail.com
}

Zarca, C. 2013. Compression Hosiery and foam Sclerotherapy, p.39. In: Bastos, Francisco Reis. Anais do V Simpósio Internacional de Flebologia [Blucher Medical Proceedings n.1 v.1]. São Paulo: Blucher, 2014

http://dx.doi.org/10.5151/medpro-flebo-SIF_20
Benefits of graduated elastic compression stockings following ultrasound-guided foam sclerotherapy of the great saphenous vein: comparison of the effectiveness of three devices in reducing pain in a randomized, double-bind, exploratory trial.

\section{Objectives}

The main objective is to compare the effectiveness of three graduated elastic stockings in reducing pain related to ultrasound-guided foam sclerotherapy of the great saphenous vein, in an exploratory trial.

Secondary objectives are to compare, between the three devices, the rate of successful sclerosis, the incidence of serious and unserious adverse events, the ease of putting on and removal the compression hosieries as well as the compliance.

\section{Patients and Methods}

115 patients were randomized into three product groups: 1) class I (10-15 mmHg); 2) class III (with pressure centered at $25 \mathrm{mmHg}$ ); 3) class III (20-36 mmHg). Compression stockings were worn for 21 days. Pain was evaluated each day using a visual analog scale (VAS) and consumption of analgesics was reported by the patient. The rate of successful great saphenous sclerosis, either in one or more procedures, and the occurrence of serious and unserious adverse events were also evaluated. Finally, the comfort of the three stockings and their ease of putting on and removal were all assessed using a VAS score.

\section{Results}

The sclerosis with post-treatment compression using graduated stockings was successful in 93\% patients. The need for additional sclerosis after the first procedure was inversely proportional to the pressure exerted by stockings (close to the significant threshold between $20-36 \mathrm{mmHg}$ and $10-15 \mathrm{mmHg}: \mathrm{p}=0.07)$. Inflammation rate was inversely correlated to the pressure level, in a significant manner between $20-36 \mathrm{mmHg}$ and 10 $15 \mathrm{mmHg}$ devices $(p=0.03)$. 
The pain experienced during the study was low and the difference between the stockings was not significant. Analgesics intake for venous pain was minor but remained nevertheless significantly lower in the class III group with pressure centered at $25 \mathrm{mmHg}$ compared to class III (20-36 $\mathrm{mmHg}$ ), with respectively $11 \%$ and $31 \%(p=0.038)$. The ease of putting on and removal was inversely related to the compression level.

\section{Conclusion}

Wearing compression stockings seems to enhance the efficacy of foam sclerotherapy of the great saphenous vein. Sclerotherapy followed by compression has a high success rate at 21 days and appears almost painless, whatever the pressure exerted by the stockings. The differences between three gratuated elastic stockings were minor. Therefore, we cannot strongly recommend any one of three.

Key words: compression stockings, foam sclerotherapy. 